inclination in the upper fragment to obey the action of the adductors, which was overcome partly by the application of splints having a contrary bearing, and partly by accommodating the lower part of the limb to the constrained posture of the upper.

Nourishment and stimuli were freely administered. At the end of the fourth day the knee-joint became painful, and subsequently somewhat tense by effusion into its cavity. At the end of ten days the swelling began to subside; and at the end of the third week it had disappeared. The progress of the case, in other respects, was most satisfactory. Suppuration set in, and the wound began to heal.

At the expiration of six weeks the healing process was completed, and firm consolidation of the ends of both fractured bones had taken place. After another fortnight the lad walked; and in the course of three months from the occurrence of the accident his gait appeared to be almost as perfect as before the accident.

Pains were taken to compare the respective lengths of the two limbs, and particularly of the two thighs. There had been no overlapping whatever of the ends of the bones in the thigh that was simply fractured, so that its length was in all probability the same after the repair of as before the accident; and the most careful measurement could detect but very little shortening, not more than half an inch in the length of the mutilated limb. An abundance of bony matter had been thrown out in the site of the fracture, but it did not appear to interfere with the movements of the joint, or with the vessels and nerves in the neighbourhood.

Cases of the kind just reported are of sufficient moment to justify a few remarks. Even simple traumatic separation of the lower epiphysis from the femur has been followed by serious consequences. Mr. Canton, in the eleventh volume of the "Pathological Transactions," records a case, and alludes to a second, in which he had to excise the joints on account of this accident. Mr. Hutchinson has, however, seen several recoveries. When complicated with a wound in the flesh, this accident is liable to be attended with very grave results, determined, however, very much by the tissues involved in the wound, and its extent. Mr. Hutchinson mentions a case in the fifteenth volume of the "Pathological Transactions" which closely resembled the one under Mr. Gay's care, with, however, one very important exception-viz., that in Mr. Hutchin son's case the popliteal vessels and nerves were torn across. Mr. Adams performed amputation in that case. The museum of St. George's Hospital contains a preparation in which the epiphysis was separated from the shaft of the bone and twisted upon itself, with a wound of the knee-joint, in a lad aged sixteen, who is said to have fallen from a height of eighty feet. Amputation was performed with success.

The question of primary amputation in Mr. Gay's case turned entirely upon the apparent immunity from harm of the main vessels and nerves of the limb; it affords ibundant proof that, under favouring circumstances, a limb so injured can be saved, and that with the most trifling detriment to the powers of locomotion.

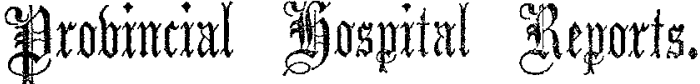

\section{CAMBRIDGESHIRE ASYLUM.}

\section{INJURY TO THE HEAD; CURIOUS MENTAL SYMPTOMS RECOVERY.}

(Under the care of Dr. G. Mackenzie Bacon.)

THE following case is interesting, not only as regards its symptoms, which were unusual, and the result, but also from the patient being able to recall all the past, and, on his recovery, describe his own sensations and give his own view of his case. It is seldom that we are able to get in mental disease a patient's "autobiography," so to speak, and to learn from himself how he has felt and observed and thought during the period that he has been separated from the sane community by his malady; but such revelations are very instructive. If driven to a definition of this condition, Dr. Bacon would call it acute dementia; but it seems in such cases as though a veil were drawn between the mind and its external manifestations, and that while the patient's actions make him to the outer world "insane," there remains behind a consciousness which registers every event, while at the same time volition is paralysed.
The patient, a boy of fifteen years of age, was admitted into the asylum on the 14th of March, 1867. In the August previous he fell from a tree, and had concussion of the brain, for which he was treated in the hospital for two weeks, and about a week afterwards returned to his work in a printing office. He soon found he was not so well as before his accident, being more irritable, easily upset by ordinary annoyances, and he also had a good deal of vertigo, and often staggered in the streets. He went on much the same till early in March, when he got into a state of delirium, and was eventually brought to the asylum. Up to the time of the accident he ailed nothing, and was of more than average intelligence. His mother is an inmate of this asylum, and one of her uncles was insane. $\mathrm{He}$ says that at the onset of the delirium he was haunted by a particular smell, which seemed to overpower him. When he went to church the people seemed to be singing all out of tune (mistaking his own discord for theirs); that he heard railway whistles, and thought the Fenians were coming; that it seemed to him all the people were leaving the town; that afterwards his mind was in a constant confusion, and he was found on a doorstep at night, saying he had no home and did not know where he was.

On admission he was restless, frequently undressing himself, seemed "lost" and stupid, and would hardly answer a question. After a few days he improved, talked with some intelligence, and began to employ himself, but soon relapsed. For nearly a fortnight he remained in a stupid state, shuffled about the ward with his arms partly extended and head inclined forwards, the saliva streaming from his mouth, and with a half-painful, half-imbecile look. He would say hardly a word, had to be moved about to his meals, and remained in the same state most of the night. He could not be induced to take food for two or three days, and resisted any forcible efforts to feed him; but after the passage of an cesophageal tube, through which wine and beef-tea were poured, he did not resist so much. This state continued, with various intermissions, during which he would brighten up and seem pretty well for six or eight weeks, after which time he rapidly improved, recovering his intelligence suddenly, and his health more slowly.

The chief point to be noted as regards treatment is the benefit he seemed to derive from enemata. Observing that at the onset of these curious attacks he was constipated, he was ordered copions and regular enemata, which always did him good, and apparently hastened his cure. Since then his bowels have acted normally.

He has since his recovery shown himself a very sharp lad, and tried to encourage his mother to exert herself. The curious point is that the lad perfectly remembers all that has passed since his admission, and says he was quite helpless to aid himself, though he desired to do so. He says, when he was first put in a bath he thought he was going to be drowned, and resisted accordingly; and he feared suffocation when the tube was passed down his throat, and exclaimed, "Let me die." These trifles point a moral if they do not "adorn a tale" and show how a patient's actions may be interpreted, though they are often hastily disposed of by such a term as excitement, violence, \&c. The lad has been for six weeks in a satisfactory state, and seems to all appearance well, though he has occasional headache.

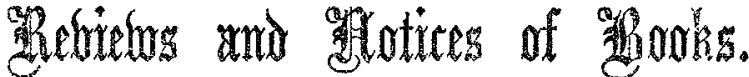

Lectures on Clinical Medicine. Delivered at the Hôtel Dieu, Paris. By A. Troussead, Professor of Clinical Medicine in the Faculty of Medicine, Paris; Member of the Imperial Academy of Medicine; Commander of the Legion of Honour Grand Officer of the Order of the Lion and the Sun of Persia; Ex-Representative of the People in the National Assembly; \&c. \&c. Translated and Edited, with Notes and Appen dices, by P. Victor BAzIRE, M.D. London and Paris, Assistant-Physician to the National Hospital for the Paralysed and Epileptic, \&c. London: Hardwicke.

THrs is the Third Part of the translation, and, with Parts I. and II. in the plan of publication, constitutes Volume I. Accordingly it closes with an index of the subjects of the previous lectures and of those contained in this part. The diseases treated of in the present section are: Cerebral Rheumatism; Exophthalmic Goitre, or Graves's Disease; Angina Pectoris; Asthma; Whooping-cough; Hydrophobia. It is enough to 